\title{
Cultura afro-brasileira nas escolas: do conhecimento ao respeito
}

\author{
DOI: 10.47224/revista master.v6i11.160
}

\author{
Danilo Faria de Moura \\ Maria Luiza de Borba Alves \\ Andressa Cristine Vieira da Silva \\ Bruna Correia dos Santos \\ Evelyn Aparecida Alves \\ Milena Aparecida de Oliveira \\ Thayná Rodrigues Alcântara Tavares
}

e-mail:danilofmoura@yahoo.com.br

\section{Resumo}

O presente artigo, tem como objetivo discorrer sobre a importância de trabalhar a cultura afro-brasileira e afrodescendente nas escolas públicas e privadas em nosso país, com o propósito de promover uma conscientização crítica acerca da temática abordada, promovendo uma sensibilização patriota nos alunos e professores, mostrando que é preciso conhecer a verdadeira história sobre suas raízes e cultura. Para isso, foi utilizado a aplicação de um formulário em que professores de diversos sistemas educacionais foram questionados sobre a aplicação da lei 10.639/03, que prevê a obrigatoriedade da aplicação do ensino da cultura afro-brasileira nas escolas, e por consequência sua conscientização histórica. As informações teóricas foram levantadas utilizando-se da metodologia de pesquisa bibliográfica e para o desenvolvimento deste estudo foram percorridas etapas propostas pela metodologia de problematização Arco de Maguerez. Buscou-se alcançar esse pontapé inicial de um diálogo reflexivo crítico sobre a cultura brasileira, suas origens e suas marcas atualmente. Conclui-se que muitas escolas, sejam elas privadas ou públicas, ainda possuem práticas suficientes que atendam aos pressupostos da lei 10.639/03.

Palavras-chave: Cultura afro-brasileira; Ensino; Conscientização; Aprendizagem.

\begin{abstract}
This article aims to discuss the importance of working on Afro-Brazilian and Afro-descendant culture in public and private schools in our country, with the purpose of promoting a critical awareness about the topic, promoting a patriotic awareness in students and teachers, showing that it is necessary to know the true story about their roots and culture. To this end, a form was used in which teachers from different educational systems were questioned about the application of law 10.639/03, which provides for the mandatory teaching of Afro-Brazilian culture in schools, and consequently their historical awareness. The theoretical information was gathered using the bibliographic research methodology and, for the development of this study, the steps proposed by the Arco de Maguerez methodology were followed. We tried to achieve this kick-off of a critical reflective dialogue about Brazilian culture, its origins, and its current marks. We conclude that many schools, whether private or public, still have sufficient practices that meet the requirements of Law $10.639 / 03$.
\end{abstract}

Keywords: $\quad$ Afro-Brazilian culture; Teaching; Awareness; Learning.

\section{INTRODUÇÃO}

O presente artigo é resultante das atividades desenvolvidas no Curso de Pedagogia, no componente curricular "Projeto Integrador VII Educação das Relações Étnico-raciais e história e cultura afro-brasileira, africana e indígena", do sexto e sétimo período, do primeiro semestre de 2020.
Abordou-se sobre a importância de trabalhar os diferentes aspectos da cultura afrodescendente nas escolas, visto que este é um assunto que deve ser tratado nas instituições com o intuito de informar, conscientizar, sensibilizar e apoiar toda a comunidade escolar igualmente. Todo o avanço cultural na educação não se deu por um acaso, "é na verdade um dos sinais mais significativos de um 
novo lugar político e social conquistado pelos chamados movimentos negros e antirracistas no processo político brasileiro, e no campo educacional em especial" (ABREU e MATTOS, 2008, p. 6). Mesmo que já exista uma lei que amparava este assunto, pode-se inferir através de estudos teóricos que essa temática ainda é um tabu para a sociedade brasileira, que em sua maioria negou incansavelmente a existência do preconceito e do racismo.

“Art. 26-A. Nos estabelecimentos de ensino fundamental e médio, oficiais e particulares, torna-se obrigatório o ensino sobre História e Cultura Afro-Brasileira. § 1․ O Conteúdo programático a que se refere o caput deste artigo incluirá o estudo da História da África e dos Africanos, a luta dos negros no Brasil, a cultura negra brasileira e o negro na formação da 2 sociedade nacional, resgatando a contribuição do povo negro nas áreas social, econômica e política pertinentes à História do Brasil. §2으 Os Conteúdos referentes à História e Cultura AfroBrasileira serão ministrados no âmbito de todo o currículo escolar, em especial nas áreas de educação Artística e de Literatura e História Brasileiras." (BRASIL, 2003 apud FREIRE, 2007, p. 103)

Para a realização do artigo, utilizou-se a metodologia da problemática com Arco de Maguerez, tendo como o foco a abordagem da cultura afro-brasileiras nas escolas, do setor público e privado. Utilizou-se de um questionário respondido por alguns professores para a observação da realidade, e posterior revisão bibliográfica para o embasamento teórico dos assuntos apresentados. O levantamento de informações teóricas se deu por meio da metodologia de pesquisa bibliográfica, sendo suas principais fontes bibliotecas virtuais e o repositório acadêmico disponíveis na internet.

"As pluralidades culturais podem permitir problematizar de forma criativa a multiplicidade (ou homogeneidade) cultural que efetivamente compõe cada ambiente escolar" (ABREU; MATTOS, 2008, p. 8). Desta forma a educação consegue obter diversas formas de como abordar a temática da pluralidade cultural, em seus aspectos sociais, além de promover aptidão ao conhecimento de culturas diferentes, até mesmo para o processo da internalização do respeito nas escolas.

O objetivo geral deste estudo é investigar sobre a aplicação das diretrizes da LBD (Lei de Diretrizes Básicas da Educação Nacional) e das Diretrizes curriculares nacionais para a educação das relações étnico-raciais e para o ensino de história e cultura afro-brasileira e africana, referentes à inclusão da temática História e Cultura Afro-Brasileira nos currículos escolares. Os objetivos específicos compreendem a análise das práticas educativas referentes a essa temática durante o calendário anual escolar, a inserção efetiva da Lei 10.639/03 no currículo escolar e propor alternativas para que as instituições de ensinos fomentar positivamente esse assunto.

A partir desta busca pela problemática, definiu-se como objeto de estudo: a falta de formação continuada e seus impactos na capacidade do professor para abordar a diversidade étnicocultural. Levantou-se o questionamento: Trabalhar essa cultura abordando todos os seus aspectos pode mudar esses alunos para que se tornem mais questionadores e empáticos como cidadãos pertencentes a uma cultura miscigenada, na maioria afrodescendentes? É possível proporcionar e influenciar futuras mudanças psicossociais em todos os envolvidos neste projeto, sejam eles discentes, docentes ou leitores?

Após a introdução serão apresentados, sequencialmente, a observação da realidade, as justificativas, a delimitação da problemática, os pontos chave elencados, o desenvolvimento a partir da teorização, as hipóteses de solução, os relatos de aplicação à realidade e as conclusões finais.

\section{OBSERVAÇÃO DA REALIDADE}

A escola tem um papel muito importante: o de socializar, problematizar, debater e transmitir conhecimento sobre a cultura afrodescendente, de modo que ela seja conhecida e respeitada, não só pela sua herança histórica cultural, mas por ser quem é parte da história do nosso país.

A escola pode ser considerada como um dos principais agentes nesse processo. Todavia se a escola não realiza um trabalho crítico e comprometido com os diversos segmentos raciais presentes no seu 
interior; se ela mesma não se preocupa e se interessa em realizar essa discussão, continuará atuando como uma instituição que reforça e reproduz o racismo presente na sociedade. (GOMES, 1995 apud NUNES, 2011, p. 44)

A observação da realidade foi realizada de forma online, devido ao isolamento social, em consequência da pandemia da Covid-19. Para sua efetivação, por meio da ferramenta Google Formulário, foram encaminhados questionários para profissionais da área da educação que atuam na cidade de Araguari e região via WhatsApp, na qual foram questionados sobre a temática Educação das Relações Étnicosraciais e história e cultura afro-brasileira, africana e indígena, de forma anônima para obtenção de informações referentes à temática e como se dá o desenvolvimento dela nas instituições de ensino. 0 perfil dos professores respondentes foi:

\section{Faixa etária:}

- $88,3 \%$ entre 20 e 35 anos;

- $\quad 16,7 \%$ entre 36 e 50 anos.

Sexo:

- $\quad 100 \%$ feminino;

Nível de formação:

- 83,3\% graduação;

- $16,7 \%$ especialização.

\section{Atuação em instituições educacionais de que segmento:}

- 50\% públicas municipais;

- $50 \%$ instituições Privadas/particulares.

Mediante esses resultados apurados foi possível realizar uma análise mais precisa sobre o processo de desenvolvimento da temática História e Cultura Afro-Brasileira nas instituições de ensino. Destacase que uma grande porcentagem das entrevistadas confirma que sua abordagem, até então, não se encontra totalmente consolidada nas instituições de ensino, mas apenas no processo de desenvolvimento.

Esse fato infringe a lei 10.639/03, que estabelece a obrigatoriedade da inclusão da temática História e Cultura Afro-Brasileira nas redes de ensino. Foi possível analisar, também, que a maioria dessas instituições não viabiliza a formação continuada para os professores, resultando na falta de conhecimento e habilidades referente a temática e ocasionando que os estudantes não agreguem valores, respeito, habilidades e conhecimento relativos ao tema.

\section{JUSTIFICATIVA}

A ideia veiculada na escola de um Brasil sem diferenças, formado originalmente pelas três raças - o índio, o branco e o negro - que se dissolveram dando origem ao brasileiro, também tem sido difundida nos livros didáticos, neutralizando as diferenças culturais e, às vezes, subordinando uma cultura à outra. Divulgou-se, então, uma concepção de cultura uniforme, depreciando as diversas contribuições que compuseram e compõem a identidade nacional. (BRASIL, 1998 apud ABREU e MATTOS, 2008, p. 7).

De fato, os materiais escolares, baseiam-se em uma base uniforme, em que se dá a desvalorização de cada cultura, acabando por depreciar suas especificidades. A ideia de uma identidade homogênea no Brasil, parece fantasiosa, porém muitos brasileiros acreditam nela. O próprio fato de existir uma cultura "mestiça" já se deve uma referenciação de onde veio, como veio, como se manteve atualmente. Coloca-se no centro das discussões o seguinte questionamento: Como propagar um ensino de uma valorização históricacultural-social em que não houve conscientização por meio do professor e da gestão escolar?

Justifica-se o desenvolvimento desse estudo em virtude das dificuldades que as instituições de ensino ainda apresentam para estarem aderentes ao que propõe a LBD e a Lei $10.639 / 03$. Esse fato pôde ser evidenciado através da pesquisa realizada, apresentada na observação da realidade. Os resultados quantitativos e os relatos destacam que as escolas ainda estão em processo de adesão ao que a lei rege, porém muitas se encontram ainda por fazer/atender o que a lei reformula.

Em primeiro lugar, é importante esclarecer que ser negro no Brasil não se limita às características físicas. Trata-se, também, de uma escolha política. Por isso, o é quem assim se define. [...] É importante tomar 
conhecimento da complexidade que envolve o processo de construção da identidade negra em nosso país. Processo esse marcado por uma sociedade que, para discriminar os negros, utiliza-se tanto da desvalorização da cultura de matriz africana como dos aspectos físicos herdados pelos descendentes de africanos. Nesse processo complexo, é possível, no Brasil, que algumas pessoas de tez clara e traços físicos europeus, em virtude de o pai ou a mãe ser negro(a), se designem negros; que outros, com traços físicos africanos, se digam brancos. É preciso lembrar que o termo negro começou a ser usado pelos senhores para designar pejorativamente os escravizados e este sentido negativo da palavra se estende até hoje. [...] (BRASIL, 2004 apud ABREU e MATTOS 2008, p. 10).

A questão cultural afrodescendente ainda é um tabu, dado como apenas a escravização do povo africano, não reconhecendo como um dos principais contribuintes da cultura atual. Nos livros escolares a cultura africana e seu contexto histórico ainda é apresentada como um ensejo o fim da escravidão, deixando a lei atual de cotas como uma singela reparação a esse contexto. Todavia, faz-se necessária a valorização e a devida representação do que realmente foi a escravização, suas marcas e, principalmente, a visão dos povos escravizados, portadores de uma cultura rica, uma identidade, uma história e uma educação. A comunidade escolar deve compreender que a escravidão não será amenizada pela lei de cotas, e que ela apenas diminuirá os impactos que deixou à população negra atualmente, que ainda carrega o peso das correntes. Jamais um país poderá amenizar algo tão brutal, mas, os cidadãos devem ensinar a valorização devida à chamada minoria negra e parda, que corresponde a cerca de $50,6 \%$ da população brasileira (HERINGER, 2010, p. 17) que se faz presente em todo o território nacional.

Muitos professores não conhecem a realidade do ponto de vista de quem sofre o racismo e não conhecem a história da colonização sob a ótica do negro, replicando suas crenças baseadas em versões que têm como verdade aos seus alunos. Frente a esse cenário a educação ganha papel de destaque, 0 que confirma a necessidade de que essa temática seja trabalhada nos currículos das escolas.

\section{PROBLEMA}

O estudo da cultura africana e afro-brasileira tornase imprescindível no contexto da atualidade, considerando a constituição do povo brasileiro, pois conforme dados do IBGE, datados de 2008, a população brasileira é composta por $48,8 \%$ de brancos e $50,6 \%$ de negros (pretos e pardos), segundo autodeclaração dos informantes (HERINGER, 2010, p. 17).

A maioria da população brasileira é composta de negros, fato que reafirma a necessidade das escolas e professores precisarem urgentemente trabalhar a cultura afrodescendente e africana em sala de aula, durante todo o ano letivo e não somente em datas comemorativas. Deve-se abordar igualmente tanto a visão europeia quanto africana, para que assim todos os alunos se sintam representados durante as aulas.

A partir das respostas coletadas pela pesquisa realizada com os professores na observação da realidade, constatou-se que na maioria das instituições o trabalho acerca da cultura afrodescendente ainda é um trabalho que ainda não está sendo cumprido pelas escolas. Verificou-se, ainda, que pelo menos metade destes professores afirmaram não ter material didático, nem oportunidades de gozar de uma formação continuada. Quanto a questão do preconceito entre os alunos, indicaram que estão tentando realizar este trabalho, porém ainda não é algo consolidado nas escolas que atuam.

A partir das respostas obtidas pelo questionário, identificou-se que algumas questões apresentam grande inconformidade com 0 proposto pelas diretrizes governamentais. Essas questões foram:

- 1.a- Os conteúdos e temáticas relacionadas ao ensino da história $\mathrm{e}$ culturas africanas e afro-brasileira e dos indígenas são tratados em todos os níveis e modalidades de ensino?

- 2.a- Existe no acervo escolar, muitos e variados materiais didáticos, livros, brinquedos vídeos que contemplem as questões raciais e os conteúdos da História da África e dos afro-brasileiros e indígenas, disponíveis para o uso dos estudantes e educadores? 
- 2.c- Possui acervo, promove estudos e socializa publicações, cursos, documentos e legislações relativas à implementação das Leis 10.639/03 e 11.645/08, junto aos (as) seus (suas) profissionais?

- 4.a- Os educadores (as) já conseguem fazer uma mediação pedagógica fundamentada nos momentos em que os estudantes passam por situações vexatórias de discriminação e racismo no ambiente escolar?

- 5.d- Investe na formação continuada para os educadores (as)?

A partir desta problemática, definiu-se como objeto de estudo:

- De que modo a falta de formação continuada pode interferir na capacidade do professor trabalhar esse tema em sala de aula?

- Trabalhar essa cultura abordando todos os seus aspectos pode mudar esses alunos para que se tornem mais empáticos enquanto cidadãos?

Este estudo é de grande relevância, visto que a partir destes questionamentos e estudos teóricos será possível proporcionar e influenciar uma futura mudança psicossocial em todos os envolvidos neste projeto, sejam eles discentes, docentes ou leitores.

\section{PONTOS CHAVE}

Elaborar currículos abertos às distintas manifestações culturais demanda uma nova postura por parte da comunidade escolar. É indispensável superar as perspectivas eurocêntricas ainda muito presentes nas escolas e buscar a valorização dos múltiplos sujeitos sociais. $A$ própria lei que incentiva o ensino de história e cultura afro-brasileira e africana também inclui a discussão sobre a diversidade étnico-racial no Brasil. Estas medidas contribuem para a reeducação das relações entre os vários grupos sociais constituintes da sociedade brasileira, provocando o questionamento das relações étnico-raciais baseadas em preconceitos e na desqualificação do outro. (FELIPE e TERUYA, 2014 p. 122).
Realmente, uma educação baseada em apenas em uma perspectiva social, acaba-se por não abraçar a multiculturalidade presente no cenário escolar. 0 ambiente escolar traz gera o conflito de toda a existência de um contexto histórico-social anterior. Os profissionais responsáveis por essa mediação precisam estar aptos a abraçar e intermediar o processo de conscientização, valorização e a importância da representatividade em todos os ambientes sociais.

As possíveis causas para os problemas identificados remetem a falta de formação continuada para os professores, que por consequência não conseguem trabalhar a pluralidade cultural com seus alunos em sala de aula, visto que não possuem um referencial teórico apropriado para lidar com situações que podem acontecer na escola. Assim, um dos fatores condicionantes maiores identificados remetentes a dificuldade de trabalhar a cultura afrodescendente e africana nas escolas é a escassez de materiais didáticos referentes a visão afro-brasileira do processo de colonização.

A contemplação da problemática levantada permite uma melhor compreensão das causas do problema, que por consequência viabiliza o encontro de possíveis soluções. Entende-se que os fatores que acabam contribuindo consideravelmente na formação do problema apontado são:

- Os conteúdos relacionados às questões raciais não são abordados com frequência e pontualmente durante o ano letivo;

- Não é constantemente trabalhado o desenvolvimento da criticidade, empoderamento e respeito com os alunos;

- Os professores não têm incentivo ou auxílio para formação continuada e materiais didáticos que contemplem as questões raciais (livros, brinquedos, vídeos):

A partir dos pontos chave selecionados, foram realizados estudos teóricos para aprofundamento e melhor compreensão do tema definido. 


\section{TEORIZAÇÃO}

Os estudos teóricos proporcionarão uma melhor explanação acerca do tema eleito e dos pontos chave definidos, que consequentemente auxiliará na escolha das possíveis hipóteses de solução para o problema levantado anteriormente. Esses estudos foram realizados através da ferramenta Google acadêmico e foram escolhidos vários artigos científicos que serviram como base para as explanações aqui contidas.

Cada sistema cultural está sempre em mudança. Entender esta dinâmica é importante para atenuar o choque entre gerações e evitar comportamentos preconceituosos. Da mesma forma que é fundamental para a humanidade a compreensão das diferenças entre povos de culturas diferentes, é necessário saber entender as diferenças que ocorrem dentro do mesmo sistema. (LARAIA, 2003, p. 101)

É importante frisar que até 2003 não havia uma lei federal que exigisse a inclusão da história da África e dos povos indígenas no currículo escolar no Brasil, dessa maneira era muito mais comum os livros escolares omitirem ou ignorarem a história de luta dos negros brasileiros, ou mesmo citarem pouquíssimas coisas sobre o assunto, de modo que passasse despercebida a importância de se conhecer as contribuições do povo negro para a formação da identidade do país, que é fruto da uma acentuada miscigenação.

É notório que os livros didáticos pouco remetem à da história de resistência, de como os negros buscam ressignificar sua cultura, crenças e seu modo de vida, e comprova-se por registros históricos que eram tratados como posses e eram transportados como mercadorias para trabalharem até a exaustão.

Infelizmente essa é a realidade do país hodiernamente, visto isto as leis $n^{\circ} 10.639 / 03$ promulgada em 2003 e a lei $n^{\circ} 11.645 / 08$ em 2008, visam garantir a obrigatoriedade de ensino da cultura afrodescendente e africana em escolas públicas e privadas do ensino fundamental ao ensino médio, evidenciando e valorizando a participação desses indivíduos e dessa cultura na construção da sociedade brasileira.

\section{A ABORDAGEM DAS QUESTÕES ÉTNICO RACIAIS NA EDUCAÇÃO DURANTE O ANO LETIVO}

A desconstrução de uma cultura banalizada, certamente é um desafio que o Brasil tem enfrentado durante séculos. O país vem de um passado de desonra em que as pessoas eram escravizadas, vendidas e compradas como mercadoria barata, sem valor, um suplício desumano, baseado em seu tom de pele, sua cultura, sua condição social e financeira, fator de redução do bom trabalhador ao escravo, sem direitos, sem salário, sem moradia própria, sem honra e sem dó.

Diante o exposto faz-se importante refletir sobre a triste realidade que historicamente tenta-se reparar, e cabe questionar: A que preço? De qual forma? Os brasileiros, nem sequer entendem a necessidade de uma valorização cultural, afinal, são levados a breve crença, muitas vezes estabelecida pela escola, que a escravidão e suas consequências, ficaram no passado, e que hoje vive-se em um país totalmente homogêneo e pluricultural.

Nesse sentido, as pluralidades culturais
podem permitir problematizar de forma
criativa a multiplicidader (ou
homogeneidade) cultural rue
efetivamente compõe cada ambiente
escolar. Podem ajudar a investigação, na
sala de aula, na escola e no bairro, sobre as
identidades construídas pelos alunos ou a
eles atribuídas. Todos os alunos se
atribuem as mesmas categorias de cor,
religião ou ascendência? Estamos num
ambiente multiétnico e plural do ponto de
vista cultural, religioso ou musical? Como
isso se produziu historicamente? O tema
transversal da pluralidade cultural,
entendido de forma dinâmica e histórica,
possui um grande potencial de inclusão e
de educação para a tolerância, objetivos
centrais a serem perseguidos pelos
educadores. (ABREU e MATTOS, 2008, p.
15)

A importância do ensino das culturas que desenvolveram a cultura brasileira, conhecida como cultura mestiça, por suas influências dos povos africanos, dos índios, portugueses, italianos, entre outros, trouxe a necessidade de uma contextualização no ensino de história, que vá além 
pluralidade cultural estabelecida pelos PCN's (Parâmetros Curriculares Nacionais) e suas orientações referentes ao respeito às outras culturas. É preciso ir além do respeito, é necessário desconstruir a insignificância das culturas.

O povo brasileiro é formado da junção da cultura indígena, negra e branca, que vai além de costumes hierárquicos, sem limitar a importância de cada cultura. Nestes aspectos identificou-se necessário o aprofundamento na temática nos livros e aulas de história, em seu parecer, criando-se as DCNs (Diretrizes Curriculares Nacionais) para a educação das relações étnico-raciais e para o ensino de história e cultura afro-brasileira e africana, em que se aprofunda na contextualização da cultura e sua história nas unidades curriculares vigentes nas escolas.

O "reconhecimento" ainda exige o questionamento das visões sobre as relações raciais no Brasil, assim como a valorização e o respeito à história da resistência negra e da cultura dos africanos e seus descendentes. Recentes pesquisas sobre a organização e os significados da família escrava, sobre as lutas dos escravos e libertos pela realização de suas festas e crenças, sobre as fugas, quilombos e revoltas, ou sobre a luta dos próprios escravos e seus descendentes pela abolição já têm recebido espaço de divulgação, embora ainda pequeno, nos livros didáticos, nos cursos de atualização de professores e em revistas de grande circulação. (ABREU e MATTOS, 2008, p. 12)

É máster destacar que leis são baseadas em interesses políticos, buscam uma coerência entre as elas, porém, o que se fará a partir se sua vigência cabe às escolas e aos professores definirem por meio de sua abordagem para instigar alunos em uma formação de cidadãos conscientes e principalmente críticos.

\section{CRITICIDADE, EMPODERAMENTO E RESPEITO EM SALA DE AULA}

Em consonância ao exposto, o que é apresentado na sala de aula atualmente ainda é uma aprendizagem com baixo significado, que não instiga os alunos a serem críticos, a valorizarem e conhecerem sobre o tema, sobre as leis, inclusive a própria lei Áurea de 13 de maio de 1888. Não somente por esta data, que foi sancionada a Lei Imperial no 3.353, que determinava a abolição da escravatura, entretanto todas as leis e ações que culminaram na elaboração e aplicação da referida lei. É destaque que foi um processo extremamente lento, contribuindo para que os políticos e senhores feudais mantivesse o controle dos escravos por mais tempo.

Com base em toda história sobre o processo da abolição da escravatura e a forma como ela é retratada nas escolas, optou-se por discorrer sobre como trabalhar a conscientização do tema no ambiente escolar e como criar uma consciência patriota e crítica neste processo, de forma a aniquilar preconceitos e apresentar aos alunos a história de luta, resistência e vitórias de um povo de cultura rica e que merece ser cada vez mais conhecida e respeitada.

É evidente que o ambiente escolar é um espaço de suma importância para promover a diversidade, mudanças, valorizar o sujeito como homem de direitos e igualdade. É por meio da educação e de seu contato com os demais sujeitos que o homem vai se construindo enquanto ser humano não de maneira isolada, mas de maneira coletiva. (SOUZA, 2015, p. 13).

Diante disso, foi implementado a lei 10.639 de 09 de janeiro de 2003, que torna obrigatório o ensino de História e Cultura afro-brasileira no componente curricular na educação básica, com isso a escola possui uma grande responsabilidade de abordar a temática étnico-racial no currículo, gerando discussões e reflexões perceptíveis referentes aos povos afrodescendentes.

A escola deve trazer essas questões para a sala de aula, de modo que mostre a verdadeira história desses povos utilizando diferentes recursos didáticos a fim de proporcionar uma maior discussão sobre o tema e principalmente ser uma oportunidade de valorização e auto aceitação do povo negro e indígena, ou seja, proporcionar aos alunos não apenas uma aprendizagem dessa temática, mas fazer com que a partir dessa discussão os alunos afrodescendentes passem a auto identificar-se como pessoa negra (SOUZA, 2015, p. 11) 
Desse modo, é extremamente importante pensar também no aluno afrodescendente, na qual, alguns negros acabam se inferiorizando, negando a sua própria identidade/raça por motivos de exclusão, discriminação e preconceito sofridos. Diante desse contexto, é essencial que os docentes reflitam sobre suas ações e práticas pedagógicas, para que estejam capacitados e qualificados para abordar a temática étnico-racial de uma forma crítica e responsável, que conscientize os alunos de uma maneira a valorizar e respeitar esses povos, bem como a diversidade cultural.

\section{FORMAÇÃO CONTINUADA DOS PROFESSORES E DISPOSIÇÃO DE MATERIAIS DIDÁTICOS SOBRE TEMÁTICAS ÉTNICO RACIAIS}

Através de estudos teóricos realizados pode-se inferir que o caminho para a construção de uma perspectiva igualitária é a pluralidade étnico racial nas práticas educativas, visto que a maioria das instituições de ensino não contemplam todas as etnias que se fazem presentes no brasil, que geralmente abordam a cultura europeia como uma cultura universal, se esquecendo de contemplar a cultura afrodescendente e indígena, que evidentemente participaram ativamente da construção da sociedade brasileira.

A história ensinada na escola brasileira ainda expressa o machismo, o regionalismo e o modo de representar o país brancocêntrico herdado de uma visão eurocêntrica. $\mathrm{O}$ currículo escolar trabalhado nas salas de aula oculta as diversas vozes e culturas processadas em seu contexto, contribuindo para a marginalização de uma parcela da população brasileira. (FELIPE e TERUYA, 2014, p. 115)

A escola é um espaço de grande influência na formação da identidade de seus alunos, o professor é um grande formador de opiniões que influenciará ativa e diretamente seus educandos. Ele precisa estar preparado e ter um olhar atento para lidar com as diversas situações que podem ocorrer em sala de aula durante o ano letivo, para que possa intervir adequadamente, desestimulando as práticas racistas e preconceituosas que podem ocorrer. Esse profissional precisa conhecer e entender esta cultura para que consiga repassar seus conhecimentos aos seus alunos de forma clara e objetiva, visando formar cidadãos conscientes e livres de preconceitos, que sabem respeitar e ter empatia pelo próximo.

O professor é, dentro da sala de aula, responsável pela formação de opiniões dos alunos, por isso as concepções e os conteúdos trabalhados por ele devem estar livres de preconceitos, para não acabar formando indivíduos racistas ou mesmo frustrando um aluno que pertença a uma dessas classes social, racial ou financeira vítimas de discriminação. (FERREIRA, 2010, p. 4)

A falta de formação continuada de professores acaba dificultando esse trabalho, por mais que essa pareça uma temática fácil de ser abordada, ou até algo inexistente, o preconceito e o racismo estão fortemente permeados na sociedade brasileira. A formação identitária desses discentes poderá ficar prejudicada se o docente não possuir a uma preparação adequada para tratar este assunto da maneira mais assertiva possível, contemplando todas as vertentes das melhores formas possíveis. Segundo Ferreira (2008, pág. 95) “Nesse sentido, uma formação profissional que contemple subsidiar o professor e o acadêmico com conhecimentos e informações que os levem a respeitar as diferenças, e que ensine que as diferenças são algo positivo, se torna imprescindível."

Professores e alunos sofrem ainda com a insuficiência ou até inexistência de materiais didáticos e de apoio adequados para o trabalho a acerca da cultura africana e afrodescendente no âmbito escolar. Esse fator acaba prejudicando a qualidade de ensino e aprendizagem acerca da igualdade racial na escola. Em relação a esta questão, ressaltou-se a falta de publicações no MEC com propostas pedagógicas e de instrumentos práticos para a aplicação em sala de aula.

Em síntese, partir dos estudos teóricos realizados acerca dos pontos chaves, ficou evidente a importância de cursos de formação continuada e materiais didáticos para que os professores tenham o embasamento teórico e materiais para trabalhar em sala de aula essa temática que é extremamente importante de ser trabalhada no âmbito escolar. 


\section{HIPÓTESES DE SOLUÇÃO}

A partir das reflexões realizadas através das leituras selecionadas e confecção da teorização baseada em estudos teóricos, fez-se possível proporcionar a apresentação de diversas alternativas para a solução dos problemas encontrados ao longo destes estudos. Sendo elas:

- Proporcionar a professores da rede pública e privada um curso online de formação continuada acerca do trabalho com a cultura afrodescendente;

- Promover palestras e oficinas aos professores com a finalidade de apresentar e orientar pedagogicamente sobre o Ensino da História e Cultura Afrobrasileira e Africana nas escolas.

- Buscar apoio da Secretaria Municipal da Educação e/ou patrocinadores para a disponibilização de materiais e recursos didáticos adequados para os professores abordarem a temática em sala de aula.

- Prover projetos que abordem a temática das Relações Étnicos-raciais, apresentando teatro, música, vídeos, discussões, debates acerca do ensino da História e Cultura Afro-brasileira e africana, que valorize a cultura e os povos afros sensibilizando toda a comunidade escolar.

Ao levar em consideração estas hipóteses selecionadas, acredita-se que a melhor opção para aplicação e solução de boa parte dos problemas encontrados é promover palestras e oficinas aos professores com a finalidade de apresentar e orientar pedagogicamente sobre o Ensino da História e Cultura Afro-brasileira e Africana nas escolas, pois assim pode-se conscientizar e auxiliar esses profissionais em seus trabalhos pedagógicos de acordo com o que prevê a constituição brasileira.

\section{APLICAÇÃO À REALIDADE}

Ao analisar as hipóteses de solução definidas, decidiu-se que destas a mais apropriada para a aplicação à realidade é a promoção de palestras e oficinas aos professores com a finalidade de apresentar e orientar pedagogicamente sobre o Ensino da História e Cultura Afro-brasileira e Africana nas escolas.

A ação consiste em convidar professores de escolas públicas e privadas para a participação das atividades, em que seria desenvolvida uma palestra, seguida de uma roda de conversa e debates, e por fim oficinas, com uma ministração enriquecida e bem elaborada com convidados e docentes acadêmicos juntamente com a escola.

A participação e colaboração é o objetivo central, para criar um debate rico e, principalmente, crítico à abordagem correta do tema em questão. Deve-se manter o foco na aprendizagem no processo de ressignificação que a escola deve abordar em seu currículo, transcendendo a sala de aula, chegando aos pátios, e as vidas dos alunos, gerando uma conscientização coletiva.

Contudo, infelizmente, devido ao cenário atual da pandemia do Covid-19, não foi possível realizar a aplicação à realidade, pois as escolas encontravam-se fechadas, sem previsão de retorno no momento do desenvolvimento dessa pesquisa.

\section{CONSIDERAÇÕES FINAIS}

Tendo em vista o exposto estudo, compreende-se que este é de extrema importância para formação acadêmica das discentes envolvidas, visto que, proporcionou realizar uma série pesquisas e estudos teóricos mais abrangentes e aprofundados acerca da temática história e cultura afro-brasileira e afrodescendentes. Por sua vez, se trata de um assunto que merece mais atenção e destaque na educação, em que cada profissional da área deve refletir sobre a sua prática pedagógica, analisando se ela realmente está sendo implementada e contemplando os seus aspectos.

Com a realização da pesquisa entendeu-se que a lei 10.639/03 estabelece a obrigatoriedade do ensino da temática História e Cultura Afro-brasileira e Africanas, e muitas escolas, sejam elas privadas ou públicas, ainda são insuficientes na prática de ações de valorizar o tema. Faz-se necessário trabalhar arduamente para que seja excluído todo o tipo de preconceitos dentro e fora de um caminho que se faz emergente para abordar como foi, verdadeiramente, a história desses povos que tanto contribuíram, e que ainda contribuem, para o país. 
Destaca-se que todos os povos e etnias são compostas por pessoas humanas que merecem valorização e respeito. A escola evidencia-se como o lugar de transformações, mudanças, conhecimentos e humanização, direcionando os passos para a conscientização de seus alunos, para, assim, um dia, possam respirar todos o ar da igualdade de direitos, da liberdade de expressão e do respeito ao outro, independentemente de como ou quem ele seja.

\section{REFERÊNCIAS}

ABREU, Martha; MATTOS, Hebe. Em torno das Diretrizes curriculares nacionais para a educação das relações étnico-raciais e para o ensino de história e cultura afro-brasileira e africana": uma conversa com historiadores. Rio de Janeiro, v. 21, n. 41, p. 5-20, junho 2008. Disponível em: http://www.scielo.br/scielo.php?script=sci arttext \&pid $=$ S0103$21862008000100001 \& \operatorname{lng}=e n \& n r m=i s o$. Acesso em: 21 maio 2020.

AGÊNCIA BRASIL. Professores têm desafio de ensinar cultura afro-brasileira, diz diretora. Disponível em: https://agenciabrasil.ebc.com.br/educacao/noticia 2015-08/professor-tem-desafio-de-ensinarcultura-afro-brasileira-diz-diretora. Acesso em: 6 jun. 2020.

CANAL DO EDUCADOR. Lei 10.639/03 e o ensino da história e cultura afro-brasileira e africana.

Disponível em:

https://educador.brasilescola.uol.com.br/estrategi as-ensino/lei-10639-03-ensino-historia-cultura-

afro-brasileira-

africana.htm\#: :text=A\%20Lei\%2010.639\%2F03\%2 C\%20que,tema\%20da\%20escravid\%C3\%A30\%20ne gra\%20africana. Acesso em: 6 jun. 2020.

CORREIA, Milenna Silva; FERNANDES, Marcella Alves; LAGES, Laérgia Mirelly Porpino. Inclusão e valorização da cultura negra em âmbito escolar.

FELIPE, Delton Aparecido; TERUYA, Tereza Kazuko. Cultura afro-brasileira e africana nos currículos da educação básica. Revista Educação e Linguagem, v. 3, n. 4, p. 114-126, 2014
FERREIRA, E. S. Didática e relações étnicas. Revista África e Africanidades, Rio de Janeiro, v. 3, n. 9, maio. 2010. Disponível em: <Disponível em: https://goo.gl/N4og1e >. Acesso em: 4 jun. 2020.

FREIRE, Everaldo José. Afro-brasilidade, educação básica e a lei 10.639/03: vozes veladas, veludosas vozes... Estudos africanos, história e cultura afrobrasileira: Olhares sobre a lei 10.639/03, p. 95, 2007.

HERINGER, Rosana. Desigualdades raciais na educação e ação afirmativa no Brasil. In: LAIA, Maria Aparecida de; SILVEIRA, Maria Lucia da. (Orgs.). A universidade e a formação para o ensino de história e cultura africana e indígena. São Paulo: Coordenadoria dos Assuntos da População Negra/Secretaria Municipal de Participação e Parceria /Prefeitura de São Paulo, 2010.

LARAIA, Roque de Barros. Cultura: um conceito antropológico. 16. ed. Rio de Janeiro: Jorge Zahar, 2003.

NOVA ESCOLA. Os desafios para implementar história e cultura afro-brasileira e africana nas escolas. Disponível em:

https://novaescola.org.br/conteudo/12692/osdesafios-para-implementar-historia-e-cultura-afrobrasileira-e-africana-nas-escolas. Acesso em: 6 jun. 2020.

NUNES, Cicera. A cultura de base africana e sua relação com a educação escolar. Revista Metáfora Educacional, n. 10, p. 38-50, 2011.

SOUZA, Josemária Alves de Jesus. Práticas de Ensino e Valorização da Cultura Afro: construindo a autoestima do aluno afrodescendente. 2015. $40 \mathrm{f}$ TCC (Graduação) - Curso de Especialização em Educação em e Para Os Direitos Humanos, no Contexto da Diversidade Cultural, Instituto de Psicologia, Universidade de Brasília, Brasília, 2015. 